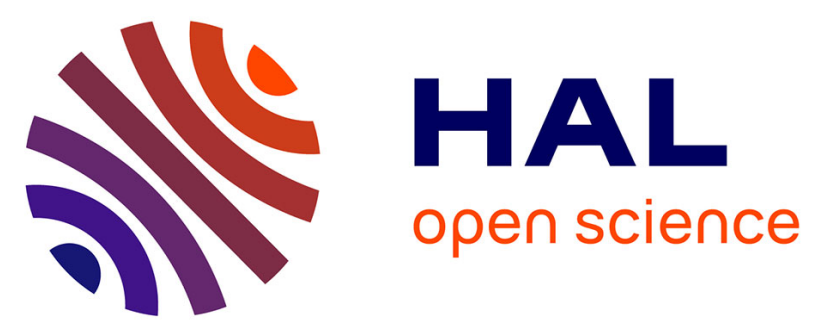

\title{
Antitumour necrosis factor- $\alpha$ therapy for hidradenitis suppurativa: results from a national cohort study between 2000 and 2013
}

E. Sbidian, C. Hotz, J. Seneschal, A. Maruani, F. Amelot, F. Aubin, C. Paul, M. Beylot Barry, P. Humbert, A. Dupuy, et al.

\section{To cite this version:}

E. Sbidian, C. Hotz, J. Seneschal, A. Maruani, F. Amelot, et al.. Antitumour necrosis factor- $\alpha$ therapy for hidradenitis suppurativa: results from a national cohort study between 2000 and 2013. British Journal of Dermatology, 2016, 174 (3), pp.667-670. 10.1111/bjd.14199 . hal-01207284

HAL Id: hal-01207284

https://hal-univ-rennes1.archives-ouvertes.fr/hal-01207284

Submitted on 13 Jan 2016

HAL is a multi-disciplinary open access archive for the deposit and dissemination of scientific research documents, whether they are published or not. The documents may come from teaching and research institutions in France or abroad, or from public or private research centers.
L'archive ouverte pluridisciplinaire HAL, est destinée au dépôt et à la diffusion de documents scientifiques de niveau recherche, publiés ou non, émanant des établissements d'enseignement et de recherche français ou étrangers, des laboratoires publics ou privés. 
Accepted Date : 14-Sep-2015

Anti-TNF $\alpha$ therapy for hidradenitis suppurativa. Results from a national cohort study between 2000 and 2013

E. Sbidian, ${ }^{1,2,3 *}$ C. Hotz, ${ }^{1}$ J. Seneschal, ${ }^{4}$ A. Maruani, ${ }^{5}$ F. Amelot, ${ }^{6}$ F. Aubin, ${ }^{7}$ C. Paul, ${ }^{6}$ M. Beylot Barry, ${ }^{8}$ P. Humbert, ${ }^{9}$ A. Dupuy, ${ }^{10}$ F. Caux, ${ }^{11}$ N. Dupin, ${ }^{12}$ P. Modiano, ${ }^{13}$ P. Lepesant, ${ }^{13}$ S. Ingen-HouszOro, ${ }^{1,3}$ E. Mahé, ${ }^{14}$ H. Bachelez, ${ }^{15}$ O. Chosidow, ${ }^{1,2,3 *}$ P. Wolkenstein, ${ }^{1,3} *$

*equally contributed

${ }^{1}$ AP-HP, Hôpitaux universitaires Henri Mondor, Département de Dermatologie, UPEC, Créteil, F94010, France;

${ }^{2}$ Inserm, Centre d'Investigation Clinique 1430, Créteil, F-94010, France;

${ }^{3}$ EA EpidermE, Université Paris-Est Créteil, UPEC, Créteil, F-94010, France;

${ }^{4}$ Hôpital Saint-André, Département de Dermatologie, Centre de référence des maladies cutanées rares; INSERM U1035, Université de Bordeaux, Bordeaux, F-33000, France;

${ }^{5}$ Hôpitaux universitaires de Tours, Hôpital Trousseau, Université François Rabelais, Service de Dermatologie, Tours, F-37000, France;

${ }^{6}$ Hôpitaux universitaires de Toulouse, Département de Dermatologie; Université Paul Sabatier, UMR CNRS 5165, INSERM 1056, Toulouse, F-31000, France;

${ }^{7}$ Université de Franche Comté, EA 3181, SFR4234; Centre Hospitalier Universitaire, Département de Dermatologie, Besançon, F-25000, France;

This article has been accepted for publication and undergone full peer review but has not been through the copyediting, typesetting, pagination and proofreading process, which may lead to differences between this version and the Version of Record. Please cite this article as doi: 10.1111/bjd.14199 
${ }^{8}$ Centre Hospitalier Universitaire, Hôpital du Haut Lévêque, Département de Dermatologie, Université de Bordeaux EA 2406, Pessac, F-33600, France;

${ }^{9}$ Université de Franche Comté, INSERM U1098, SFR4234; Centre Hospitalier Universitaire,

Département de Dermatologie, Besançon, F-25000, France;

${ }^{10}$ Centre Hospitalier Universitaire de Rennes, Hôpital Pontchaillou, Département de Dermatologie;

Inserm CIC 1414, Université de Rennes 1, Rennes, F-35000, France;

${ }^{11}$ AP-HP, Hôpitaux Universitaires Avicenne, Département de Dermatologie; Centre de Référence

MAGEC ; Université Paris 13, Bobigny, F-93000, France;

${ }^{12}$ AP-HP, Hôpitaux Universitaires Cochin, Département de Dermatologie; Université Paris Descartes Paris V, Paris, F-75014, France;

${ }^{13}$ GHICL, Hôpital Saint-Vincent-de-Paul, Département de Dermatologie, Lille, F-59000, France;

${ }^{14}$ Hôpital Victor Dupouy, Département de Dermatologie, Argenteuil, F-95100, France

${ }^{15}$ Sorbonne Paris Cité Université Paris Diderot; Service de Dermatologie, AP-HP Hôpital Saint-Louis, Paris, F-75010 France;

Corresponding author: Emilie Sbidian, Service de Dermatologie, Hôpital Henri Mondor, 51 av du Maréchal de Lattre de Tassigny, F-94010, Créteil, France, Tel: 003314981 25 01, Fax: 0033149 8125 08, emilie.sbidian@aphp.fr

Funding sources : none

Conflict of interest statement: E Sbidian, C Hotz, O Chosidow, A Maruani, F Amelot, P Lepesant, S Ingen-Housz-Oro, J Seneschal, N Dupin and P Humbert have no conflict of interest. 
E. Mahé is a consultant for Abbvie, and Pfizer; has been investigator for Pfizer, and Abbvie; and has received speaker honoraria from Abbvie, and Pfizer; H Bachelez had consulting activities for Abbvie, Amgen, Boehringer, Celgene, Lilly, Janssen, MSD, Novartis, Pfizer, Takeda; Pierre Fabre, Sandoz; C Paul had consulting activities for Abbvie, Amgen, Celgene, Janssen, Leo Pharma, Novartis; F Aubin had consulting activities for Merck Serono, MSD/Schering-Plough, Pfizer, Abbvie, Janssen, Galderma, Leo Pharma, Novartis, Astellas, La Roche Posay; M Beylot Barry had consulting activities for Janssen, Abbvie, Pfizer, Lilly, Celgene, Leo Pharma, Novartis, MSD; F Caux had received speaker honoraria from Abbvie; P Wolkenstein had consulting activities for Abbvie, Pierre Fabre, Laboratoire Expanscience; A Dupuy had consulting activities for MSD, Pierre Fabre, P Modiano had consulting activitites for Abbvie and LeoPharma.

\section{To the editor}

Hidradenitis suppurativa (HS) is a frequent chronic inflammatory skin disease typically characterized by recurrent painful, deep inflammatory nodules of the axillary, breast, groin and gluteal areas. ${ }^{1,2}$ European recommendations are mainly based on expert opinion ${ }^{3}$. Drug treatments are heterogenous (e.g., antibiotics, corticosteroids, retinoids) and lack consensus among expert centres. ${ }^{3}$ The most severe disease forms or those failing to respond to conventional drugs may be associated with worsened functional prognosis. Anti-tumor necrosis factor $\alpha$ (anti-TNF $\alpha$ ) drugs have been prescribed in these cases. The results of randomized controlled trials (RCTs) are discordant. Three RCTs concluded to the efficacy of adalimumab (ADA), ${ }^{4-6}$ and two others did not detect any difference between infliximab (IFX) or etanercept (ETA) and placebo. ${ }^{7,8}$ Finally, data from the literature and reported experiences do not conclude on the efficacy of anti-TNF $\alpha$ drugs for HS.

The aim of this study was to assess the efficacy of anti-TNF $\alpha$ drugs in patients with HS seen in routine care.

We conducted a national retrospective cohort. Patients who presented HS and who received at least one anti-TNF $\alpha$ drug during the evolution of the disease were eligible. We contacted 25 centres, This article is protected by copyright. All rights reserved. 
including mainly teaching hospitals ( $\mathrm{n}=22$ ) but also general hospitals $(\mathrm{n}=3)$. Eleven had eligible patients, 7 had no eligible patients and the 7 other centres did not respond to our requests. For each centre with eligible patients, patients were selected by a cross-examination of data from January 1, 2000 to December 31, 2013 in 3 databases (the dermatology department databases, the national database in France PMSI, Programme de Médicalisation des Systèmes d'Information and the hospital pharmacy databases). Duplicates were excluded.

A standardized form was used to record sociodemographic characteristics. Associated inflammatory diseases were also recorded, as was personal history of HS. Anatomic zones involved at least once in the history of the patient were classified as breast and armpit, follicular and gluteal involvement. ${ }^{9}$ Disease severity was evaluated at the time of clinical examination by the Hurley grade. Details of the anti-TNF $\alpha$ therapy recorded included the molecule, dosage, treatment duration, and adverse effects.

Patients were classified into 3 groups of response after first-line anti-TNF $\alpha$ treatment: complete response (resolution of all skin lesions or at least 90\% improvement), (2) partial response (at least 50\% improvement), and (3) no response. Event-free survival was measured from the date of the beginning of anti-TNF $\alpha$ treatment to the date of the first relapse or lost to follow-up. The factors that could influence progression-free survival times were tested with Cox's proportional hazards model.

Among 18 centres, we identified 67 patients with HS (37 [55.2\%] women; median age 38.0 years (range 10.9-71.8 years) who received an anti-TNF $\alpha$ drug during this 13-year period.

Characteristics of the study population are in Table 1. The most frequent anti-TNF $\alpha$ drug prescribed as first-line treatment was IFX, $5 \mathrm{mg} / \mathrm{kg}(\mathrm{n}=57 / 66,86.4 \%)$, then ADA, $40 \mathrm{mg}$ every 2 weeks $(\mathrm{n}=7 / 66$, $10.6 \%)$ and ETA, $50 \mathrm{mg}$ twice a week $(\mathrm{n}=2 / 66,3.0 \%)$. The median follow-up was 6.8 months [interquartile range (IQR) 3.6-19.1]. Eight cases (11.9\%) achieved complete response, 31 (46.2\%) partial response and $25(37.3 \%)$ no response, 3 (4.6\%) had just been treated by anti- TNF $\alpha$ drugs and 
monitoring data were not available. The median follow-up for the 3 groups was 22.8 [10.4-44.2], 13.2 [4.7-22.9] and 4.6 [1.4-7.9] months, respectively. Twelve patients (17.9\%) received 2 anti- TNF $\alpha$ drugs and $5(7.4 \%), 3$.

Factors associated with a complete or at least a partial response to first line anti-TNFa therapy in univariate and multivariate analysis are summarized Table 2. On multivariate analysis, complete response to first line anti-TNF $\alpha$ therapy was independently associated with currently smoking (hazard ratio $[\mathrm{HR}] 8.4,95 \%$ confidence interval $1.3-56.0 ; \mathrm{p}=0.03$ ) and associated inflammatory bowel or arthritis diseases (HR 6.8, 1.2-40.0; $\mathrm{p}=0.03$ ). Only one patient with an inflammatory arthritis disease who achieved complete response had received another immunosuppressive treatment (methotrexate). Partial response to first line anti-TNF $\alpha$ therapy was associated with only ADA treatment (HR 6.6, 2.219.7), $\mathrm{p}=0.001)$. In total, $5 / 7$ patients $(71.4 \%)$ receiving ADA achieved a partial response and none receiving ADA had a complete response. Four patients had to stop anti-TNF $\alpha$ treatment because of severe side effects ( 1 case each of hepatitis, lupus, repeated urinary tract infection, and pulmonary embolism).

Our results suggest modest and inconsistent efficacy of anti-TNF $\alpha$ therapy for moderate to severe HS. Complete and persistent clinical responses were rarely obtained (11.9\%) and partial response was achieved in $46.2 \%$ of patients. These results are consistent with a retrospective Spanish cohort study of 19 patients. ${ }^{10}$ Anti-TNF $\alpha$ therapy could be efficient in this subset of patients presenting an associated inflammatory disorder.

Currently smoking was an independent factor associated with a complete response to antiTNF $\alpha$ therapy. These results are contrary to data provided by registers dealing with inflammatory arthritis. ${ }^{11}$ However, previous reports had suggested that smokers, particularly those who smoked before the HS, had a less severe form of HS than never-smokers. ${ }^{12}$ In addition, current smoking is a protective factor in other inflammatory diseases such as ulcerative colitis. ${ }^{13}$ Larger studies are needed to better determine the protective effect of tobacco use in patients with HS. 
Finally, partial response to anti-TNF $\alpha$ therapy was about 7 times higher for patients who received ADA as compared with ETA or IFX. This result highlights a possible class effect of ADA and agrees with results of other RCTs and the recent approval of ADA (40 mg weekly after initial doses of $160 \mathrm{mg}$ at week 0 and $80 \mathrm{mg}$ at week 2) as a possible treatment for patients with active moderate to severe HS by the European Medicines Agency (EMA). ${ }^{4-6,14}$ Higher dosages of ADA as mentioned above might be associated with higher response rates as compared with a standard dosage (40 mg every 2 weeks)..$^{5}$ All patients of our cohort received the standard dosage which could have undermined the overall response rate.

To conclude, anti-TNF $\alpha$ therapy in patients with moderate to severe HS seems more efficient in a subset of patients with associated arthritis or inflammatory bowel disorder. Complete and persistent clinical response, with anti-TNF $\alpha$ drugs used as a single agent, was rarely obtained. ADA seems to be more efficient than IFX and ETA. Other therapeutic strategies, such as anti-TNF $\alpha$ drugs especially higher dosages of ADA used before surgery or low dose methotrexate in combination, have yet to be assessed.

\section{Acknowledgements}

The authors are indebted to Laura Smales for her helpful review of the manuscript.

The authors are indebted to Prs MA Richard, MT Leccia, L Martin, E Delaporte and Drs A Soria, A Nassif for their prompt response to the inquest.

IRB status: The study was approved by the Ile-de-France IV (Paris, France) ethics committee (IRB), $\mathrm{n}^{\circ} 2015 / 22 \mathrm{NI}$. 


\section{References}

1 Jemec GB. Clinical practice. Hidradenitis suppurativa. N Engl J Med 2012; 366: 158-64.

2 Revuz JE, Canoui-Poitrine F, Wolkenstein P et al. Prevalence and factors associated with hidradenitis suppurativa: results from two case-control studies. J Am Acad Dermatol 2008; 59: 596-601.

3 Zouboulis CC, Desai N, Emtestam L et al. European S1 guideline for the treatment of hidradenitis suppurativa/acne inversa. J Eur Acad Dermatol Venereol 2015.

4 Miller I, Lynggaard CD, Lophaven S et al. A double-blind placebo-controlled randomized trial of adalimumab in the treatment of hidradenitis suppurativa. Br J Dermatol 2011; 165: 391-8.

5 Kimball AB, Kerdel F, Adams D et al. Adalimumab for the treatment of moderate to severe Hidradenitis suppurativa: a parallel randomized trial. Ann Intern Med 2012; 157: 846-55.

6 Sotiriou E, Goussi C, Lallas A et al. A prospective open-label clinical trial of efficacy of the every week administration of adalimumab in the treatment of hidradenitis suppurativa. $J$ Drugs Dermatol 2012; 11: s15-20.

Grant A, Gonzalez T, Montgomery MO et al. Infliximab therapy for patients with moderate to severe hidradenitis suppurativa: a randomized, double-blind, placebo-controlled crossover trial. J Am Acad Dermatol 2010; 62: 205-17.

Adams DR, Yankura JA, Fogelberg AC et al. Treatment of hidradenitis suppurativa with etanercept injection. Arch Dermatol 2010; 146: 501-4.

Canoui-Poitrine F, Le Thuaut A, Revuz JE et al. Identification of three hidradenitis suppurativa phenotypes: latent class analysis of a cross-sectional study. J Invest Dermatol 2013; 133: 1506-11.

Martin-Ezquerra G, Masferrer E, Masferrer-Niubo M et al. Use of biological treatments in patients with hidradenitis suppurativa. J Eur Acad Dermatol Venereol 2015; 29: 56-60.

Hyrich KL, Watson KD, Silman AJ et al. Predictors of response to anti-TNF-alpha therapy among patients with rheumatoid arthritis: results from the British Society for Rheumatology Biologics Register. Rheumatology (Oxford) 2006; 45: 1558-65.

Canoui-Poitrine FLTA, Revuz J, Wolkenstein P, Viallette C, Gabison G, Pouget F, Poli F, Bastuji-Garin S Smoking and hidradenitis suppurativa: risk or pronostic factor ? Results from a series of 947 patients. J Invest Dermatol 2012; 132: S70-S4.

Sicilia B, Arribas F, Nerin J et al. Risk factors for ulcerative colitis: A population-based, casecontrol study in Spain. J Crohns Colitis 2008; 2: 158-61.

European Medicines Agency.

http://ec.europa.eu/health/documents/communityregister/2015/20150728132555/anx_132555_ fr.pdf. First medicine recommended for approval for hidradenitis suppurativa. On september, 1 th 2015. 
Table 1. Initial characteristics of patients with hidradenitis suppurativa (HS) who received an antitumor necrosis factor $\alpha$ (anti-TNF $\alpha)$ drug $(\mathrm{n}=67)$

\begin{tabular}{|c|c|}
\hline Characteristics ( $\mathrm{n}=$ missing data) & $\mathbf{N}(\%)$ \\
\hline Women & $37(55.2)$ \\
\hline Age, years, median (range) & $38.0(10.9-71.8)$ \\
\hline \multicolumn{2}{|l|}{ Smoking status $(\mathrm{n}=5)$} \\
\hline Non-smoker & $19(30.7)$ \\
\hline Current smoker & $34(54.8)$ \\
\hline Ex-smoker & $9(14.5)$ \\
\hline Body mass index, $\mathrm{kg} / \mathrm{m}^{2}$, median (range) & $28.0(16.7-53)$ \\
\hline$>25$ & $48(71.6)$ \\
\hline$>30$ & $29(43.4)$ \\
\hline History of severe acne & $13(19.4)$ \\
\hline \multicolumn{2}{|l|}{ HS phenotype * } \\
\hline Classical & $32(47.8)$ \\
\hline Follicular & $14(20.9)$ \\
\hline Gluteal & $21(31.3)$ \\
\hline \multicolumn{2}{|l|}{ Highest Hurley grade $(\mathrm{n}=5)$} \\
\hline II & $16(25.8)$ \\
\hline III & $46(74.2)$ \\
\hline \multicolumn{2}{|l|}{ Associated inflammatory disorder } \\
\hline Inflammatory bowel disease & $2(3)$ \\
\hline Inflammatory arthritis & $11(16.4)$ \\
\hline Inflammatory bowel diseases or arthritis & $12(17.9)$ \\
\hline
\end{tabular}




\begin{tabular}{|l|l|}
\hline Neutrophilic skin disease & $8(12)$ \\
\hline Fist line anti-TNFa treatment $(\mathrm{n}=1)$ & $7(10.6)$ \\
Infliximab & $57(86.4)$ \\
Etanercept & $2(3)$ \\
\hline Second line anti- TNFa treatment & $12(17.9)$ \\
Adalumimab & $9 / 12(52.9)$ \\
Infliximab & $5 / 12(29.4)$ \\
Etanercept & $3 / 12(17.7)$ \\
\hline Third line anti- TNFa treatment & $5(13.4)$ \\
Adalumimab & $1 / 5(20)$ \\
Infliximab & $1 / 5(20)$ \\
Etanercept & $3 / 5(60)$ \\
\hline
\end{tabular}

Data are no. (\%) unless indicated

*Canoui-Poitrine et al, J Invest Dermatol 2013; 133:1506-11 


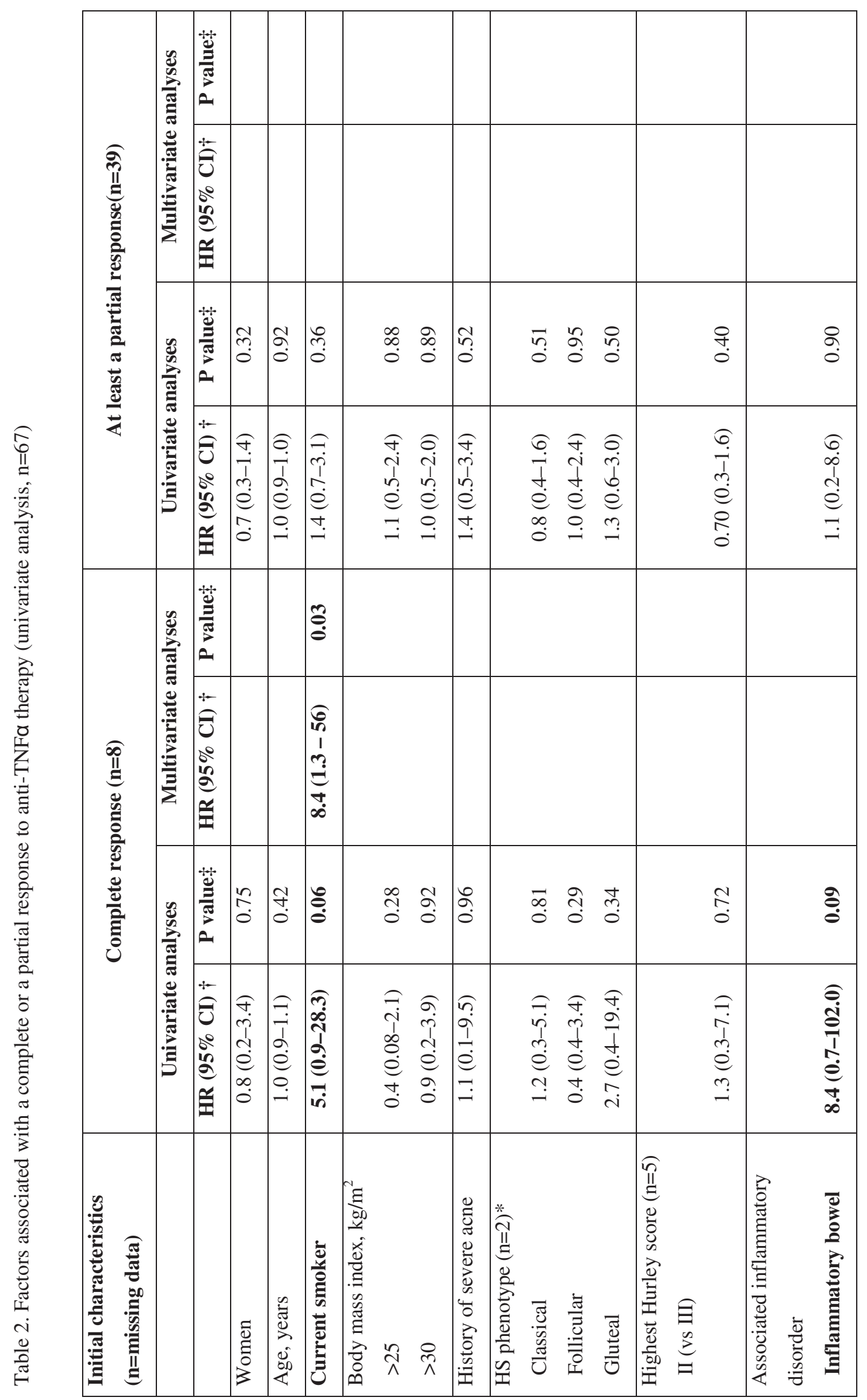




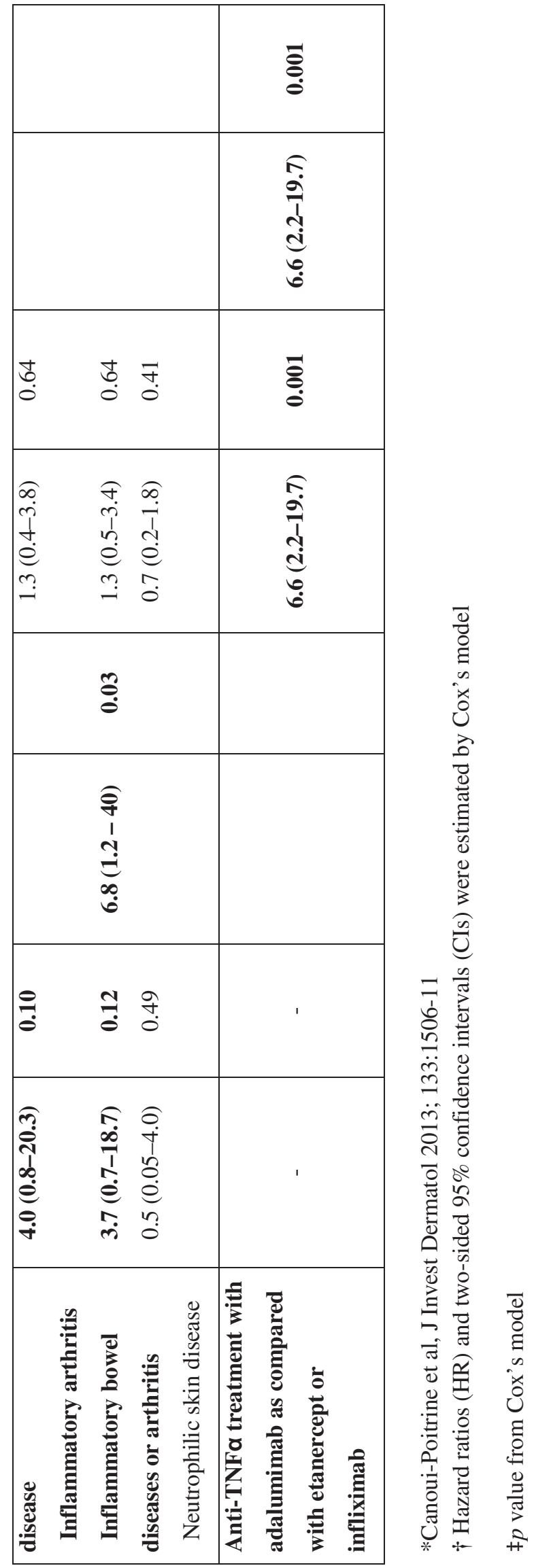

